\title{
Ameliorative effect of alpha lipoic acid and royal jelly against the side effects of cyclophosphamide in liver of albino rats
}

\author{
Manal Abdul-Hamid ${ }^{1 *}$, Nadia Moustafa', Khalid A. El-Nesr ${ }^{2}$ and Amal M. Abukhadra'
}

\begin{abstract}
Background: Cyclophosphamide (CP) is a cytotoxic anticancer drug used for the treatment of neoplastic diseases. The present study aimed to examine biochemical, histological, and ultrastructural effects of CP on rat liver and determine the hepatoprotective effects of alpha-lipoic acid (LA) or royal jelly (RJ) against CP.

Results: The present study revealed that CP-induced significant increase in hepatic marker enzymes (ALT and AST), and elevation in malonaldehyde (MDA) was concomitant with a significant decrease of superoxide dismutase (SOD). It caused histopathological changes in the liver of rat including vacuolation, infiltration, degeneration, and necrosis. Ultrastructurally, the hepatocytes appeared degenerated with multiple small- and medium-sized lipid droplets in the cytoplasm. Kupffer cell showed a shrunken nucleus. Administration of LA and RJ resulted in an obvious improvement in the altered level of ALT, AST, MDA, and SOD activities when compared with the CPtreated group in addition to marked amelioration in histopathology and ultrastructure of the liver.

Conclusions: LA is markedly effective than RJ in protecting rats against CP-induced biochemical, histopathological, and ultrastructural changes. This protection may be due to its antioxidant properties and scavenging abilities against active free radicals.
\end{abstract}

Keywords: Cyclophosphamide, Alpha-lipoic acid, Royal jelly, Antioxidant, ALT, AST, Liver, Histopathological and ultrastructural study

\section{Background}

Anticancer drugs are usually used for the treatment of cancer and have been detected in hospital effluents, wastewater treatment plant effluents, and river water samples in concentrations up to the $\mu \mathrm{g} \mathrm{L}^{-1}$ range [1].

Cyclophosphamide (CP) is an alkylating agent with antineoplastic and immunosuppressive effects. One of its metabolites is acrolein which leads to toxic side effects such as cell death and oxidative stress [2]. Moreover, CP cause toxicity in healthy tissues in addition to cancerous tissues. CP in high doses leads to acute inflammation in

\footnotetext{
*Correspondence: medo_bio@yahoo.com;

manal.mohamed3@science.bsu.edu.eg

'Department of Zoology, Faculty of Science, Beni-Suef University, Beni-Suef 62521, Egypt

Full list of author information is available at the end of the article
}

the kidney, bladder damage, and liver damage as well as apoptosis [3, 4].

$\mathrm{CP}$ is converted to acrolein and phosphoramide mustard, an agent that adds alkyl groups to oxygen and nitrogen atoms of guanine, one of the four nitrogen bases that form the DNA nucleotides, producing DNA crosslinks and introducing DNA breaks. Its cytotoxic and mutagenic effects principally occur in proliferating cells [5].

The liver is considered the center of drug metabolism and bioconversion, and the liver is rich in a collection of biotransformation enzymes. Drug bioconversion in the liver normally produces inactive metabolic end products which are excreted from the body but can also generate toxic metabolites [6]. Furthermore, the liver plays an essential role for the metabolism and detoxification of xenobiotics in the body [7] and enhanced production of

\section{Springer Open}

(c) The Author(s). 2020 Open Access This article is licensed under a Creative Commons Attribution 4.0 International License, which permits use, sharing, adaptation, distribution and reproduction in any medium or format, as long as you give appropriate credit to the original author(s) and the source, provide a link to the Creative Commons licence, and indicate if changes were made. The images or other third party material in this article are included in the article's Creative Commons licence, unless indicated otherwise in a credit line to the material. If material is not included in the article's Creative Commons licence and your intended use is not permitted by statutory regulation or exceeds the permitted use, you will need to obtain permission directly from the copyright holder. To view a copy of this licence, visit http://creativecommons.org/licenses/by/4.0/. 
free radicals, and oxidative stress can be induced during detoxification of xenobiotic [8].

$\mathrm{CP}$ leads to abnormal activities of serum enzymes that indicate cellular damage; this appears as an increase in serum transaminases ALT, AST, alkaline phosphatase (ALP), and lactate dehydrogenase (LDH) [9]. Moreover, there were increasing levels of malonaldehyde (MDA) and GST and there was a decrease in glutathione (GSH) level and superoxide dismutase (SOD) activity [10].

$\mathrm{CP}$ induced histopathological hepatotoxicity in mice which is showed by inflammation in the central vein and pyknotic nuclei in hepatic cells [11], prominent intense cellular degeneration, cellular inflammation of hepatocytes with vascular congestion and sinusoidal dilatation, and the focal area of hepatic necrosis replaced by focal hepatic hemorrhage and leukocytic cells infiltration [10].

$\mathrm{CP}$ administration leads to ultrastructural changes such as plasma membrane disruption and widespread cytoplasmic degenerative changes. Also, some endothelial cells were exhausted of organelles, and their cytoplasm only displayed a few vesicular structures. Besides, damaged endothelial cells containing large electronlucent vacuoles were often seen. Many lysosomal bodies of irregular size and shape displayed breaks in their cytoplasmic membranes, and heterogeneous density appeared in numerous Kupffer cells [12].

Many antioxidants have recently been used to inhibit oxidative damage produced by high oxidative stress attributable to CP [13]. The administration of alpha-lipoic acid (LA) which is a common antioxidant is beneficial in numerous pathologies where ROS have been concerned $[14,15]$. Because LA is a strong antioxidant, it causes a common systemic improvement including liver health $[16,17]$. Besides, LA protects the liver from fat accumulation by suppressing appetite, increasing metabolism, and reducing body weight [18].

Lipoic acid (LA) was found in mitochondria as the coenzyme for mitochondrial dehydrogenase multienzyme complexes. Exogenous supplementation with LA has been reported to increase unbound lipoic acid levels, which reduce oxidative stress both in vitro and in vivo situations and act as a potent antioxidant [19].

Royal jelly (RJ) is a natural product produced by a bee and used in medicine. The chemical structure of RJ indicates the presence of many bioactive substances including 10-hydroxydecanoic acid and 24-methylenecholesterol and also several biological and pharmacological activities [20]. Furthermore, RJ administration provides sufficient protection against the rat brain tissue function and structure [21].

$\mathrm{RJ}$ is an effective antioxidant and has a free radical scavenging capacity $[22,23]$. Besides, it has been shown to possess numerous biological activities, such as antioxidative, antibacterial, immunomodulatory, anti-inflammatory, and tumoricidal activities, and also is commonly used in commercially available drugs and health foods, in addition to cosmetics, in many countries [24]. RJ contains the 57$\mathrm{kDa}$ glycoprotein which stimulates the hepatocyte development and liver regeneration [25].

The current study carried out to study the histopathological, ultrastructure, and biochemical changes of $\mathrm{CP}$ effect on the liver and to estimate the possible protective role of LA and RJ in improving these changes.

\section{Methods}

\subsection{Chemicals}

\subsubsection{Cyclophosphamide (CP)}

$\mathrm{CP}$ was dissolved in saline, orally treated in a dose of (5 $\mathrm{mg} / \mathrm{kg}$ b.wt) and was purchased from Baxter Oncology Gmbh Kantstrasse2 D-33790 Halle, Germany.

\subsubsection{Alpha-lipoic acid (LA)}

LA was dissolved in $100 \mathrm{ml}$ ( $25 \mathrm{ml}$ di methyl sulpho oxide (DMSO) $+75 \mathrm{ml}$ distilled water), and we used $\mathrm{NaOH}$ to neutralize the solution $\mathrm{pH}=7$ and it was given orally in a dose of $25 \mathrm{mg} / \mathrm{kg}$ b.wt three times a week for 4 weeks. LA was purchased from Sigma-Aldrich Chemical Company Inc., Product of China, stored at $2-8{ }^{\circ} \mathrm{C}$, MW 206.33, mp 60-62oC, assay $\geq 98.0 \%$ (HPLC).

\subsubsection{Royal jelly (RJ)}

RJ was dissolved in distilled water and was given orally in a dose of $1 \mathrm{~g} / \mathrm{kg}$ b.wt three times a week for 4 weeks and was purchased from Safe for Pharmaceutical Products for Pharco Pharmaceuticals (stored at a temperature not exceeding $30^{\circ} \mathrm{C}$ ).

\subsection{Animals}

Sixty-four white male albino rats (Rattusnorvegicus), weighing 140-170 g, were obtained from the Egyptian Organization for Biological Products and Vaccines. The animals were housed in plastic cages with wired covers and kept under normal laboratory conditions for the different periods used. The animals were supplied with water and classic rat chow ad libitum, and they were kept under observation for a week before the start of the experiment. In our study, animal care was carried out following the European Community Directive (86/609/ EEC) and national rules; this is in accordance with the $\mathrm{NIH}$ guidelines for care and use of laboratory animals, 8th edition. This was administrated by the committee of the Zoology Department, Beni-Seuf University, Egypt. At the end of the experiment, the rats were sacrificed by anesthesia inhalation under light diethyl ether (5\%).

Then, the animals were divided into eight groups each of 8 rats.

Group 1. This group served as a control group and received saline orally. 
Group 2. This group received alkaline solution orally (to make the medium $\mathrm{pH}$ neutral).

Group 3. This group was given di methyl sulpho oxide (DMSO) orally.

Group 4. This group received an oral dose of lipoic acid ( $25 \mathrm{mg} / \mathrm{kg}$ b.wt) three times a week for 4 weeks [26].

Group 5. This group received an oral dose of royal jelly

( $1 \mathrm{~g} / \mathrm{kg}$ b.wt) three times a week for 4 weeks [27].

Group 6. This group was orally treated with CP (5 mg/ $\mathrm{kg}$ b.wt) 3 days per week for 4 weeks [28].

Group 7. This group was orally treated with CP (5 mg/ $\mathrm{kg}$ b.wt) and then received an oral dose of lipoic acid ( $25 \mathrm{mg} / \mathrm{kg}$ b.wt) three times a week for 4 weeks.

Group 8. This group was orally treated with CP (5 mg/ $\mathrm{kg}$ b.wt) and then received an oral dose of royal jelly (1 $\mathrm{g} / \mathrm{kg}$ b.wt) three times a week for 4 weeks.

\subsection{Methods}

\subsubsection{Tissue homogenate preparation}

Blood was collected and centrifuged for obtaining the serum for ALT, AST analysis; then, liver homogenate was obtained by grinding a small piece $(1 \mathrm{~g})$ of freshly excised tissue in 10 volumes of $0.9 \%$ saline solution and was kept at $-20{ }^{\circ} \mathrm{C}$ till use in the determination of superoxide dismutase (SOD), using the methods of [29], and lipid peroxidation (LPO) [30].

\subsubsection{Histological preparations}

After 4 weeks, the animals from each group were sacrificed under mild diethyl ether anesthesia. Small pieces of liver were fixed in $10 \%$ neutral buffered formalin solution for $24 \mathrm{~h}$. Liver tissue specimens were embedded in paraffin using a conventional method and then cut. Paraffin sections of some liver were stained with hematoxylin and eosin [31].

\subsubsection{Ultrastructural preparations}

At the end of the experiment (4 weeks), specimens of the liver were cut into small pieces measuring about 1 $\mathrm{mm}^{3}$ and directly fixed in fresh $3 \%$ glutaraldehydeformaldehyde at $4{ }^{\circ} \mathrm{C}$ for $18-24 \mathrm{~h}$. Then, the specimens were washed in phosphate buffer $(\mathrm{pH} 7.4)$ and then post-fixed in isotonic 1\% osmium tetroxide for $1 \mathrm{~h}$ at $4{ }^{\circ} \mathrm{C}$ [32]. Serial dehydration in alcohol was carried out. The specimens were then passed through propylene oxide solution and finally embedded in EPON epoxy resin. Semithin sections were cut from these blocks at $1.0 \mu \mathrm{m}$ thickness by ultra-cut E Reichert-Jung ultramicrotome with the aid of glass knives, stained with toluidine blue stain, and examined by light microscope to detect the area of interest. Ultrathin sections (70-90 nm) were then prepared using the ultramicrotome glass knives, stained with uranyl acetate and lead citrate [33], and examined with a Joel JEM-2100 transmission electron microscope which worked at an accelerating voltage $80 \mathrm{kV}$.

\subsubsection{Statistical analysis}

Analysis of data was performed using student ANOVA test and comparing between means using LSD (least significant difference) as outlined by IBM Corp [34].. Results were expressed as mean \pm standard error, and values of $P>0.05$ were considered non-significantly different, while those $P<0.05$ and $P<0.01$ were significantly and highly significantly different, respectively.

\section{Results}

\subsection{Determination of liver function enzymes}

\subsubsection{Determination of serum alanine transaminase (ALT)} and aspartate transaminase (AST) activities

Figures 1 and 2 indicate that ALT and AST activities were markedly increased in the $\mathrm{CP}$ group in comparison to control, slightly alkaline solution, DMSO, LA, and RJ group. Besides, the administration of LA in concomitant with $\mathrm{CP}$ and also RJ in concomitant with $\mathrm{CP}$ showed observable amelioration in these activities nearly similar to the control group.

Regarding one-way ANOVA of ALT and AST activities, it was found that there was a significant difference between $\mathrm{CP}$ group and all other groups (control, slightly alkaline solution, DMSO, LA, RJ, CP+ LA, and CP+ RJ). Also, there was no significant difference in ALT activity between control group value $(4.33 \pm 0.8 \mathrm{U} / \mathrm{L})$, slightly alkaline solution $(6.66 \pm 1.14 \mathrm{U} / \mathrm{L})$, DMSO $(8.83 \pm 1.01 \mathrm{U} / \mathrm{L}), \mathrm{LA}(7.66 \pm$ $0.95 \mathrm{U} / \mathrm{L})$, and RJ $(10.66 \pm 1.02 \mathrm{U} / \mathrm{L})$. In addition, there was no significant difference in AST activity between control group value $(10.33 \pm 0.80 \mathrm{U} / \mathrm{L})$, slightly alkaline solution $(9.16 \pm 0.79 \mathrm{U} / \mathrm{L})$, DMSO $(3.16 \pm 1.07 \mathrm{U} / \mathrm{L}), \mathrm{LA}(11.33 \pm$ $1.11 \mathrm{U} / \mathrm{L})$, and RJ $(14.00 \pm 1.36 \mathrm{U} / \mathrm{L})$.

\subsection{Determination of antioxidant parameters}

The cyclophosphamide-treated group indicated a marked increase in lipid peroxidation in the form of malonaldehyde (MDA) and decrease in superoxide dismutase (SOD) in comparison with control, slightly alkaline solution, DMSO, $\mathrm{CP}+\mathrm{LA}$, and $\mathrm{CP}+\mathrm{RJ}$ groups, although LA and RJ administration made a decrease in MDA and increase in SOD activity similar to control groups.

One-way ANOVA analysis of liver lipid peroxidation and superoxide dismutase of all groups are given in Figures 3 and 4. Nearly similar results in MDA activities were in the control, slightly alkaline solution, DMSO, CP+ $\mathrm{LA}$, and $\mathrm{CP}+\mathrm{RJ}$ groups. $\mathrm{CP}$ administration resulted in a significant $\left(P^{<} 0.001\right)$ increase in MDA level $(44.89 \pm 1.19$ $\mathrm{nmol} / \mathrm{g}$ tissue) when compared to the control group (9.55 $\pm 0.37 \mathrm{nmol} / \mathrm{g}$ tissue). And CP administration caused a significant decrease in SOD level $(43.48 \pm 1.39 \mathrm{U} / \mathrm{g}$ tissue $)$ 


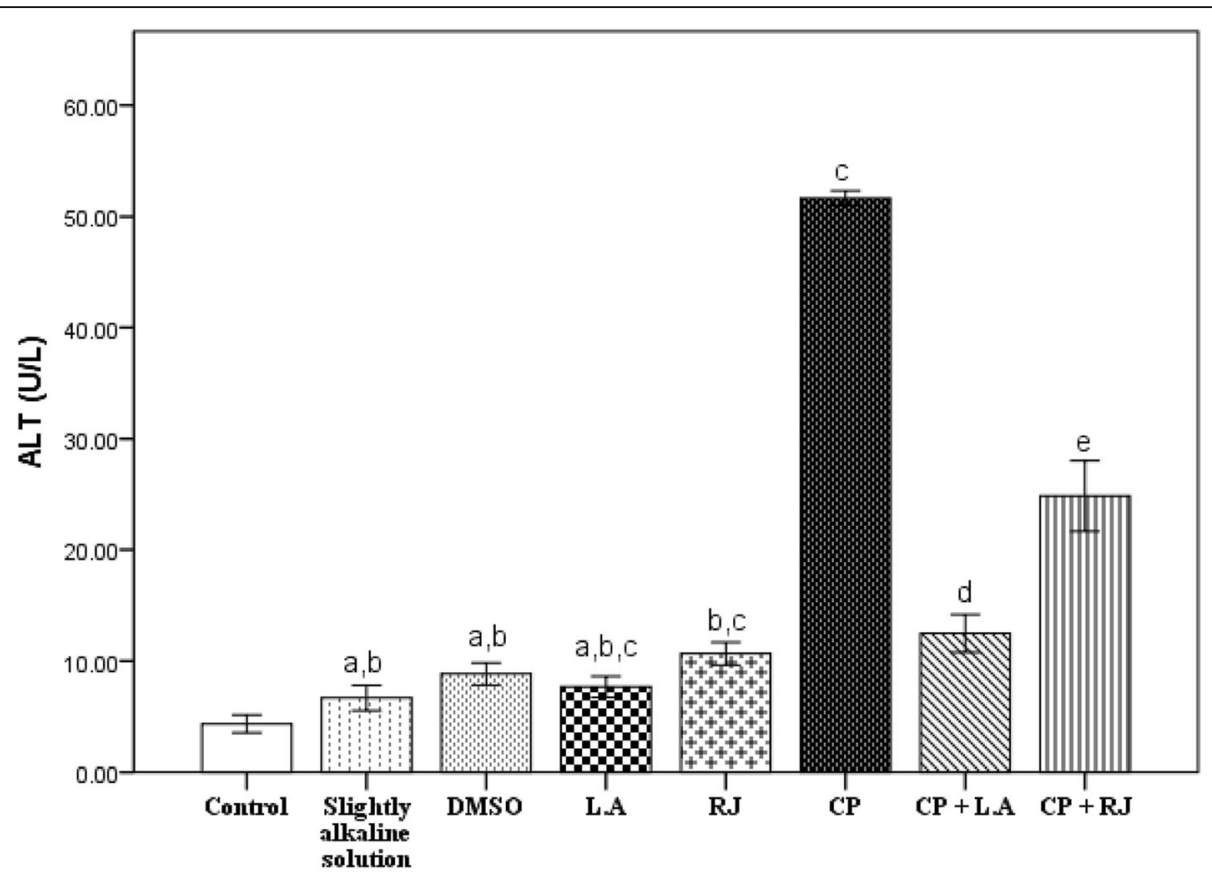

Fig. 1 Activities of serum ALT (U/L) of control, slightly alkaline solution, di methyl sulpho oxide (DMSO), alpha-lipoic acid (LA), royal jelly (RJ), cyclophosphamide (CP), cyclophosphamide plus alpha-lipoic (CP+LA) acid, and cyclophosphamide plus royal jelly (CP+RJ) for 30 days. The number of animals is 6 for each group. Data are expressed as mean \pm standard error. Values with the same superscript letter are non-significant at $P>0.05$, whereas others are significant at $P<0.05$ and highly significant at $P<0.01$

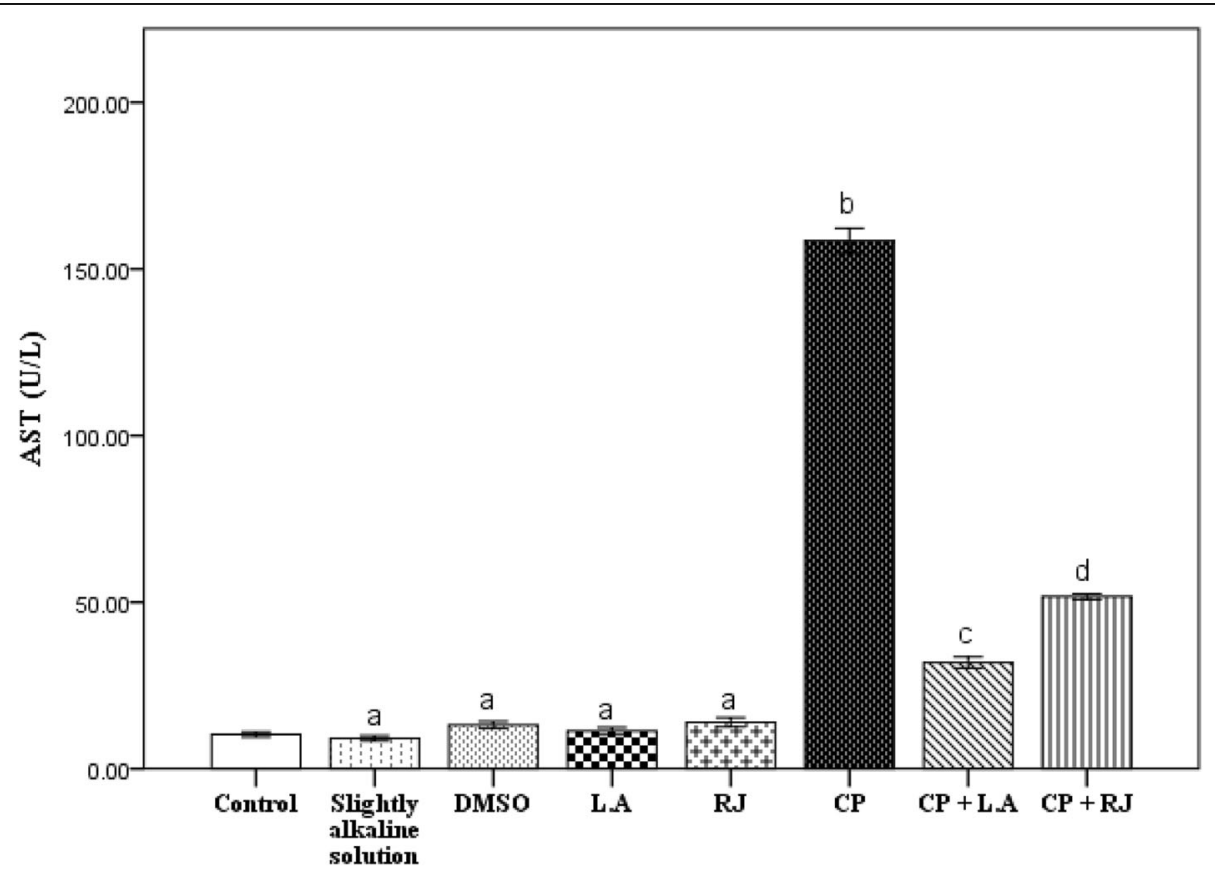

Fig. 2 Activities of serum AST (U/L) of control, slightly alkaline solution, di methyl sulpho oxide (DMSO), alpha-lipoic acid (LA), royal jelly (RJ), cyclophosphamide (CP), cyclophosphamide plus alpha-lipoic (CP+LA) acid, and cyclophosphamide plus royal jelly (CP+RJ) for 30 days. The number of animals is 6 for each group. Data are expressed as mean \pm standard error. Values with the same superscript letter are non-significant at $P>0.05$, whereas others are significant at $P<0.05$ and highly significant at $P<0.01$ 


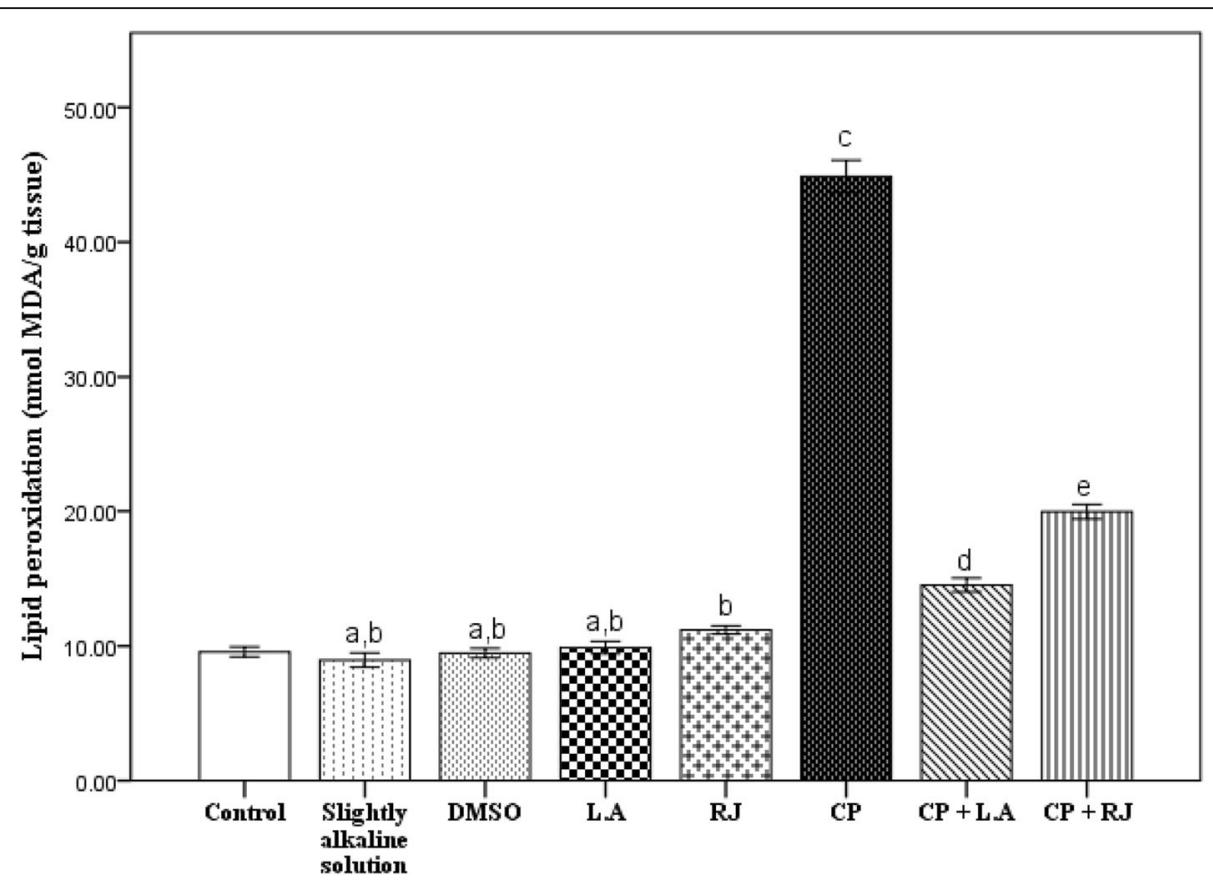

Fig. 3 Lipid peroxidation (MDA) (nmol/g tissue) of control, slightly alkaline solution, di methyl sulpho oxide (DMSO), alpha-lipoic acid (LA), royal jelly (RJ), cyclophosphamide (CP), cyclophosphamide plus alpha-lipoic (CP+ LA) acid, and cyclophosphamide plus royal jelly (CP+RJ) for 30 days in liver homogenate. The number of animals is 6 for each group. Data are expressed as mean \pm standard error. Values with the same superscript letter are non-significant at $P>0.05$, whereas others are significant at $P<0.05$ and highly significant at $P<0.01$

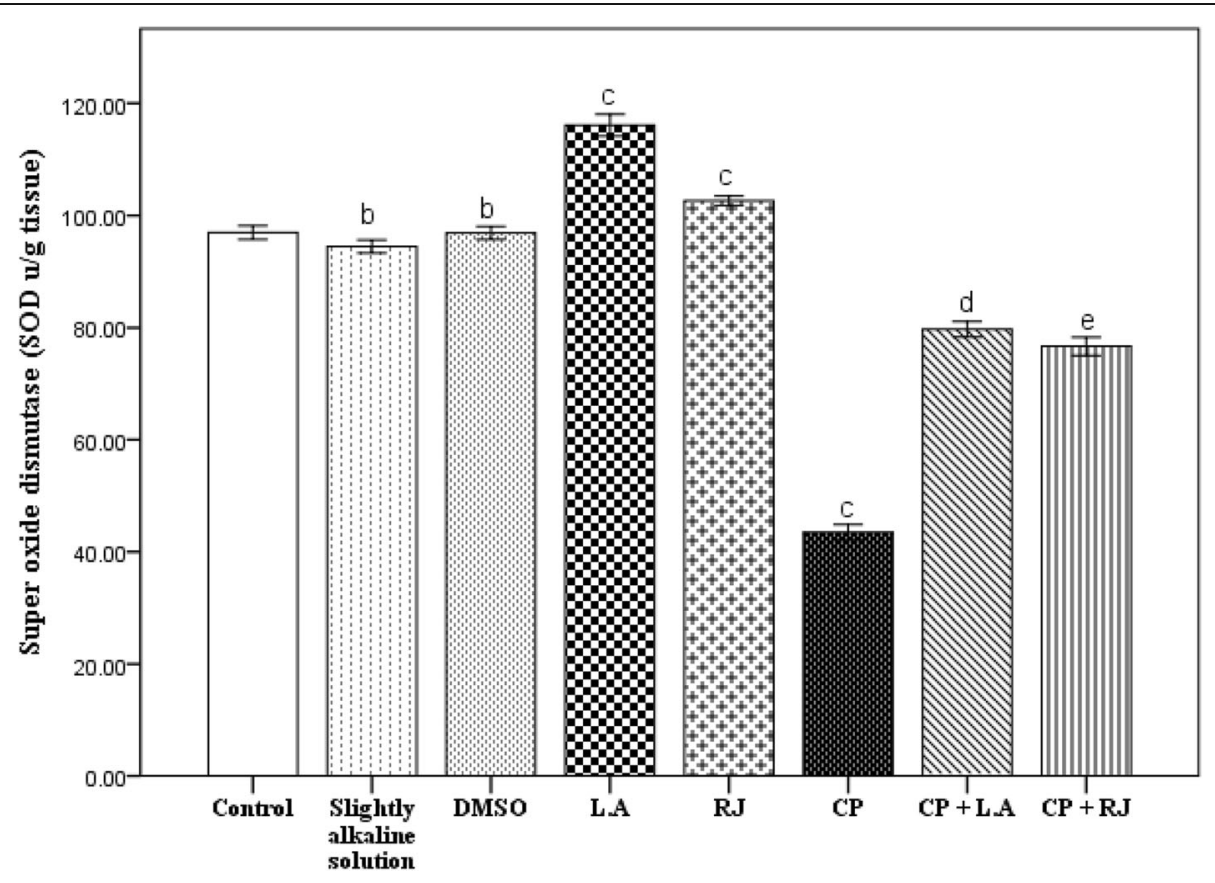

Fig. 4 Superoxide dismutase (SOD) (U/g tissue) of control, slightly alkaline solution, di methyl sulpho oxide (DMSO), alpha-lipoic acid (LA), royal jelly (RJ), cyclophosphamide (CP), cyclophosphamide plus alpha-lipoic (CP+ LA) acid, and cyclophosphamide plus royal jelly (CP+RJ) for 30 days in testis homogenate. The number of animals is 6 for each group. Data are expressed as mean \pm standard error. Values with the same superscript letter are non-significant at $P>0.05$, whereas others are significant at $P<0.05$ and highly significant at $P<0.01$ 
when compared to the control group $(96.94 \pm 1.12 \mathrm{U} / \mathrm{g}$ tissue). However, administration of $\mathrm{Al}$ and $\mathrm{RJ}$ to $\mathrm{CP}$ treated rats revealed marked amelioration in the altered level of MDA and SOD activities when compared with the $\mathrm{CP}$-treated group.

\subsection{Histopathological observations of the liver 3.3.1 Liver of control rats}

The histological examination of liver sections of control rats and alpha-lipoic acid- and royal jelly-treated rats showed their normal architecture in Fig. 5a-c, respectively. The normal liver consists of several poorly defined hepatic lobules. Each lobule is formed of cords of hepatocytes radiating from the central vein. The hepatic cords are separated by narrow blood sinusoids which are lined by Kupffer cells and endothelial cells. The hepatocytes are large polyhedral with acidophilic cytoplasm and darkly stained nuclei.

\subsubsection{Liver of cyclophosphamide-treated rats}

The portal vein was dilated and engorged with blood in addition to a marked proliferation of the bile duct (Fig. 6a). In other areas, minute to large fat globules were seen intracellularly forming a signet ring appearance (Fig. 6b). The hepatocytes appeared enlarged with the presence of empty vacuoles within the cytoplasm surrounding the nuclei in multiple areas. These vacuoles were in the form of cloudy swelling and hydropic degeneration. Moreover, pyknosis also appeared (Fig. 6c). Necrosis with lysis of hepatocytes was also found in some areas (Fig. 6d). Multifocal leukocytic infiltrations were found in the hepatic parenchyma and vacuolar degeneration in hepatocytes (Fig. 6e).

\subsubsection{Liver of rats treated with cyclophosphamide plus alpha-lipoic acid and royal jelly}

In these cases, the liver of $\mathrm{CP}+\mathrm{LA}$ and $\mathrm{CP}+\mathrm{RJ}$, respectively, showed improvement in comparison with $\mathrm{CP}$ group, central vein retained to normal structure, and both hepatocytes and blood sinusoids nearly appeared more or less similar to the control group (Fig.7a, b).

\subsection{Ultrastructural observations of the liver 3.4.1 Liver of control rats}

Ultrastructural examination of hepatocytes from animals of the control group revealed no destructive alterations with normal organelles that overcrowded the cytoplasm, particularly rough and smooth endoplasmic reticulum and mitochondria. The rough endoplasmic reticulum consists of closely packed parallel and flattened cristae. The nuclei appear spherical with one nucleolus and the normal pattern of chromatin distribution. Numerous electron-dense glycogen rosettes and bile duct with intact microvilli were detected (Fig. 8a, b). Sinusoid with normal Kupffer cell was seen (Fig. 8c).

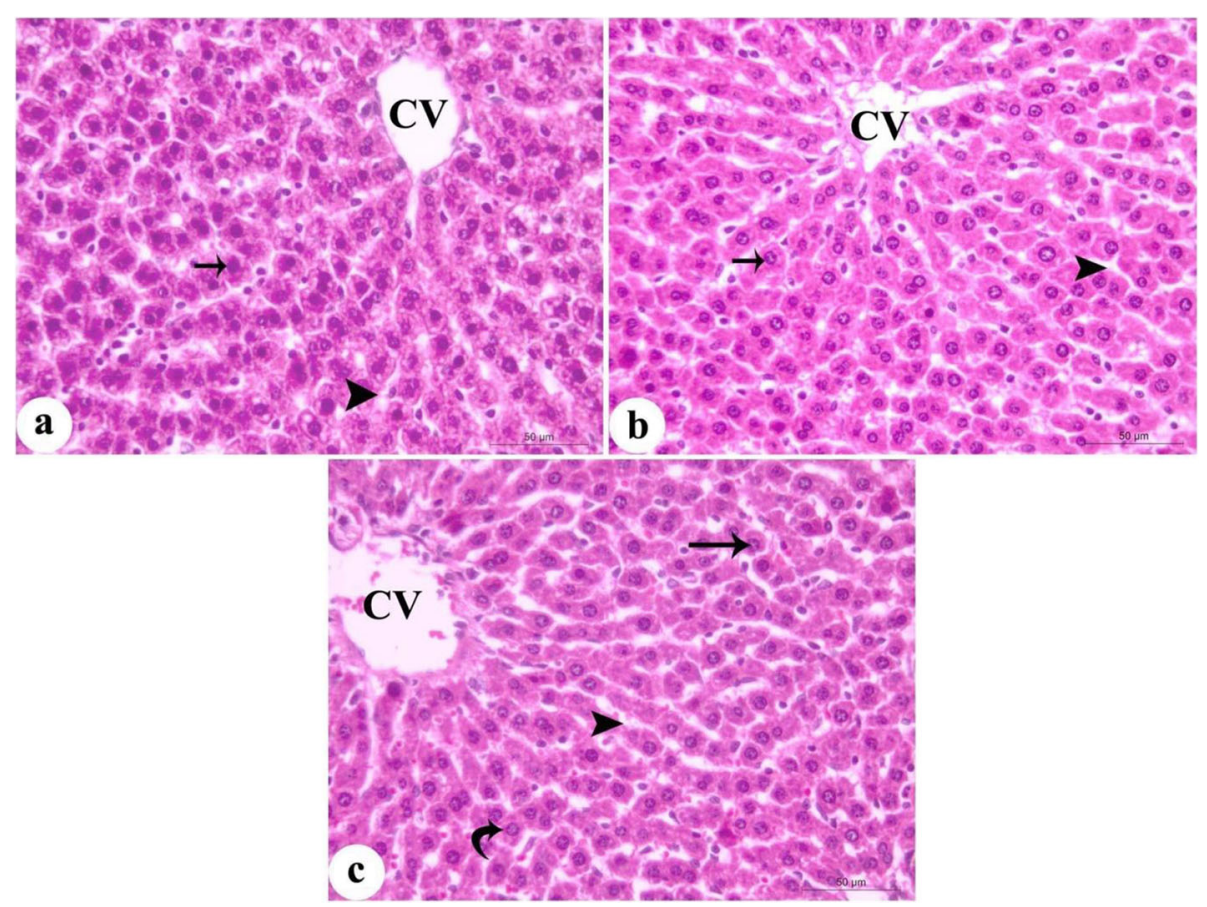

Fig. 5 a-c Photomicrograph of liver sections in rats of control, alpha-lipoic acid, and royal jelly group, respectively, stained with H\&E showing the normal histological structure of the hepatic cords, central veins (CV), and hepatocytes with round nuclei (arrow) separated by blood sinusoids (arrow head) (scale bar $=50 \mu \mathrm{m}$ ) 


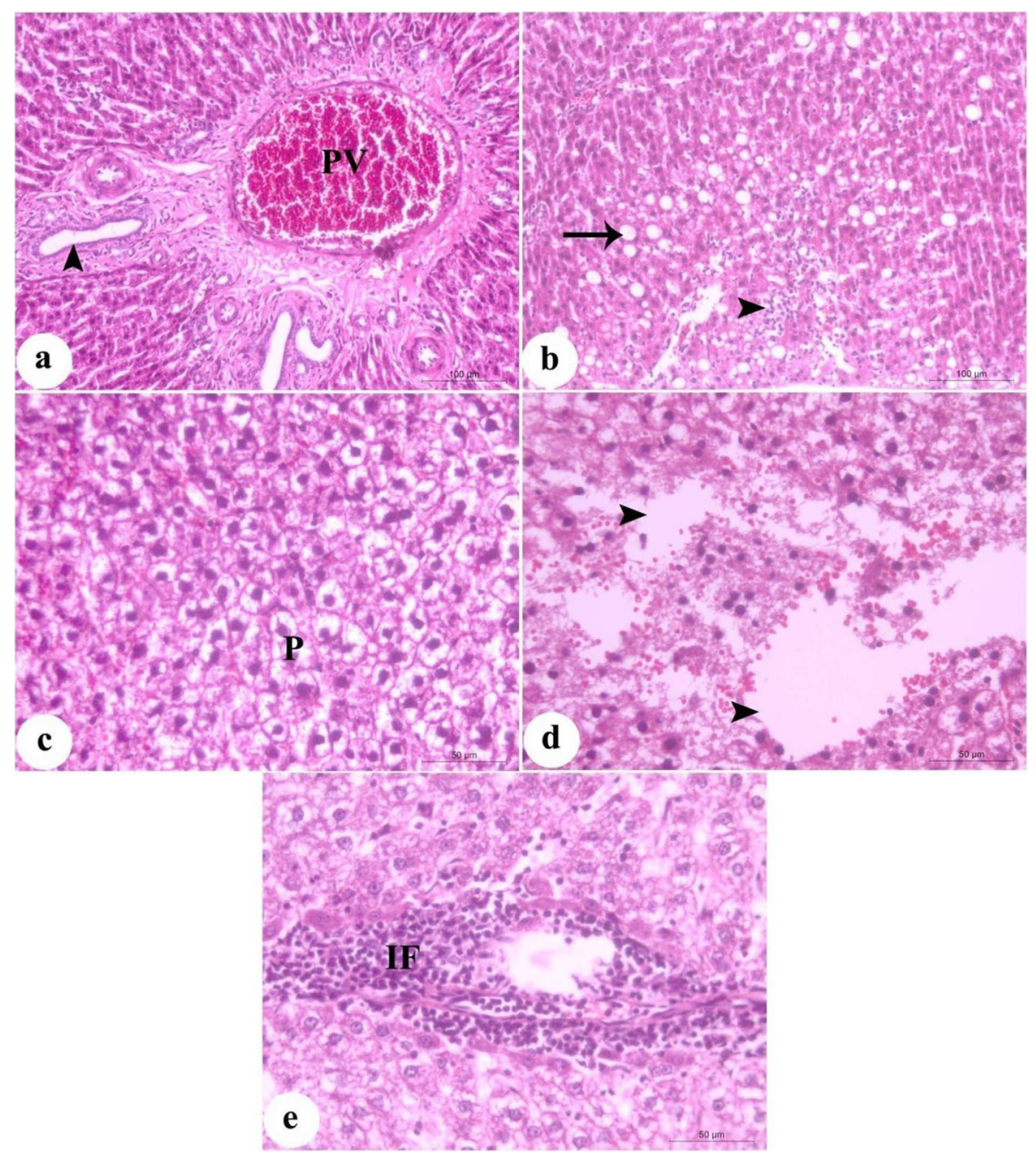

Fig. 6 a-e Photomicrograph of sections in the liver of rats of cyclophosphamide-treated group stained with H\&E. a Dilated and congested portal vein (PV), Marked proliferation of bile ducts (arrow heads). b A massive fatty change (arrow) in the form of a signet ring appearance accompanied by leukocytic infiltration (arrow heads). c Pyknosis (P). d Necrosis with lymphocyte infiltration (arrow head). e Massive leukocytic infiltration (IF) in the parenchyma and vacuolar degeneration in hepatocytes. $\mathbf{a}$, b Scale bar $=100 \mu \mathrm{m}$. c-e Scale bar $=50 \mu \mathrm{m}$

\subsubsection{Liver of cyclophosphamide-treated rats}

Degenerated hepatocytes with multiple small- and medium-sized lipid droplets in the cytoplasm, also disorganization and decrease in glycogen, dilatation in $\mathrm{ER}$, and electron-dense mitochondria, appeared in the cytoplasm (Fig. 9a). In other hepatocytes, there is marked variation in the size of mitochondria, where marked, swollen, and elongated mitochondria with illdefined cristae appeared (Fig. 9c). Moreover, dilated damaged bile duct was also seen (Fig. 9b). Vacuolations and marked collagen fibers were also observed (Fig. 9c). Kupffer cell showed a shrunken nucleus with an observed increase in the number of lysosomes in the cytoplasm (Fig. 9c, d).

\subsubsection{Liver of rats treated with cyclophosphamide plus alpha-lipoic acid and royal jelly}

The liver of CP-treated rats with alpha-lipoic acid showed marked recovery of the cytoplasm organelles and bile duct (Fig. 10a, b). Kupffer cells restored their normal structure (Fig. 10c). The liver of CP-treated rats with royal jelly showed marked recovery of the cytoplasm organelles except for a few lipid droplets (Fig. 10d). There was nearly normal appearance of the bile duct (Fig. 10e), but Kupffer cell showed a shrunken nucleus (Fig. 10f).

\section{Discussion}

Cyclophosphamide (CP) has been used in the clinical treatment of various types of cancer and autoimmune diseases and also used as an immunosuppressant after 


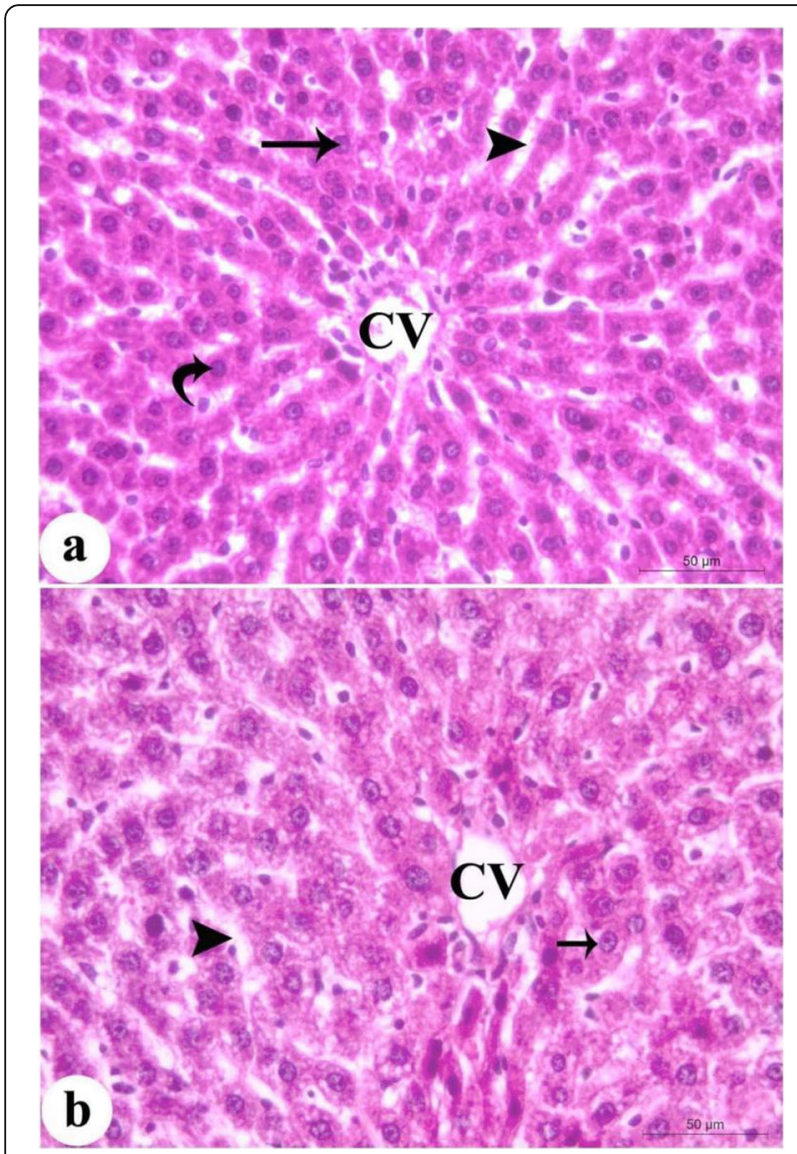

Fig. 7 a, b Photomicrograph of a section in the liver of rats of cyclophosphamide, alpha-lipoic acid, and royal jelly group, respectively, stained with $H \& E$ showing central veins (CV),

hepatocytes (curved arrow) with round nuclei (arrow) separated by blood sinusoids (arrow head) nearly similar to control group (scale bar $=50 \mu \mathrm{m})$

organ transplantations (e.g., bone marrow transplantations) [35]. The side effect of this drug is fatal hepatic damages in humans and experimental animals [36]. CP cause toxicity in healthy tissues in addition to in cancerous tissues [4].

The liver plays an essential role in the metabolism and detoxification of xenobiotic in the body [7]. Metabolism of $\mathrm{CP}$ occurs in the liver and undergoes metabolic activation by cytochrome p450 isoenzyme [37]. Enzymatic activities of serum ALT, AST, LDH, and ALP were considered sensitive indicators of hepatic injury [38] and the injury to the hepatocytes alters their transport function and membrane permeability, leading to leakage of enzymes from the cells [39]. Moreover, these enzymes under normal conditions are present in high concentrations in the liver and are released into the circulation during hepatocyte necrosis or membrane damage, as indicated by elevated serum enzyme levels [40]. So an increase in the serum ALT, AST, LDH, and ALP activities in CP-treated rats indicated hepatic cell damage. This is clear in our study as CP administration caused a significant increase in the activities of serum ALT and AST; this indicates liver damage induced by the drug and these observations are consistent also with Tripathi et al. [41].

Oxidative stress is the result of an imbalance between ROS generation and the intracellular capacity for removing ROS, subsequently leading to excessive damage in the cell [42].

Lipid peroxidation is one of the main indexes of oxidative damage started by ROS, and it has been related to the altered membrane structure and enzyme inactivation. It is initiated by the abstraction of a hydrogen atom from the side chain of polyunsaturated fatty acids in the membrane [43].

The present data exposed that CP administration produced a marked oxidative impact, as evidenced by the significant increase in LPO as well as a decrease in SOD levels as showed in the CP-treated group. These results concords with Caglayan et al. [44] and Ghosh et al. [45] who illustrated that $\mathrm{CP}$-induced lipid peroxidation. The reduction in the activities of the SOD and increase in LPO could reflect the adverse effects of CP, which imbalanced the antioxidant system in the liver tissue. CP administration has been demonstrated to be an excellent model to produce syndromes of both oxidative stress and hepatic damage [46]. The increase in lipid peroxides might result from increased production of free radicals and a decrease in antioxidant status. The oxidative stress observed in our study is in line with other reports [47], where it has been implicated in CP-induced hepatotoxicity. The generation of free radicals and other ROS as well as lipid peroxidation have been reported to be the major mechanisms in CP toxicity $[13,48]$. Such oxidative stress generates biochemical and physiological disturbances [49].

In the present study, liver revealed that $\mathrm{CP}$ induced a severe damaging effect on liver tissues. Abnormal histological findings were found in liver tissues such as infiltration, congestion, fatty changes, edema, vascular degeneration, and necrosis. These findings coincide well with the results obtained by Yagmurca et al. [13, 49, 50], Sakr et al. [50], Ince et al. [13], and Cengiz et al. [51] who illustrated that $\mathrm{CP}$ induction causes liver damage showed by dark staining, shrinkage, irregularity in the nucleus boundaries and increase in eosinophilia in the cytoplasm, as well as increases in congestion and erythrocytes accumulation in the vascular structures.

Ultrastructurally, the hepatocytes of the CP-treated group appeared degenerated with multiple small- and medium-sized lipid droplets; other hepatocytes showed swollen mitochondria with ill-defined cristae, marked collagen fibers, and damaged bile duct also appeared. Kupffer cell showed a shrunken nucleus and an increase 


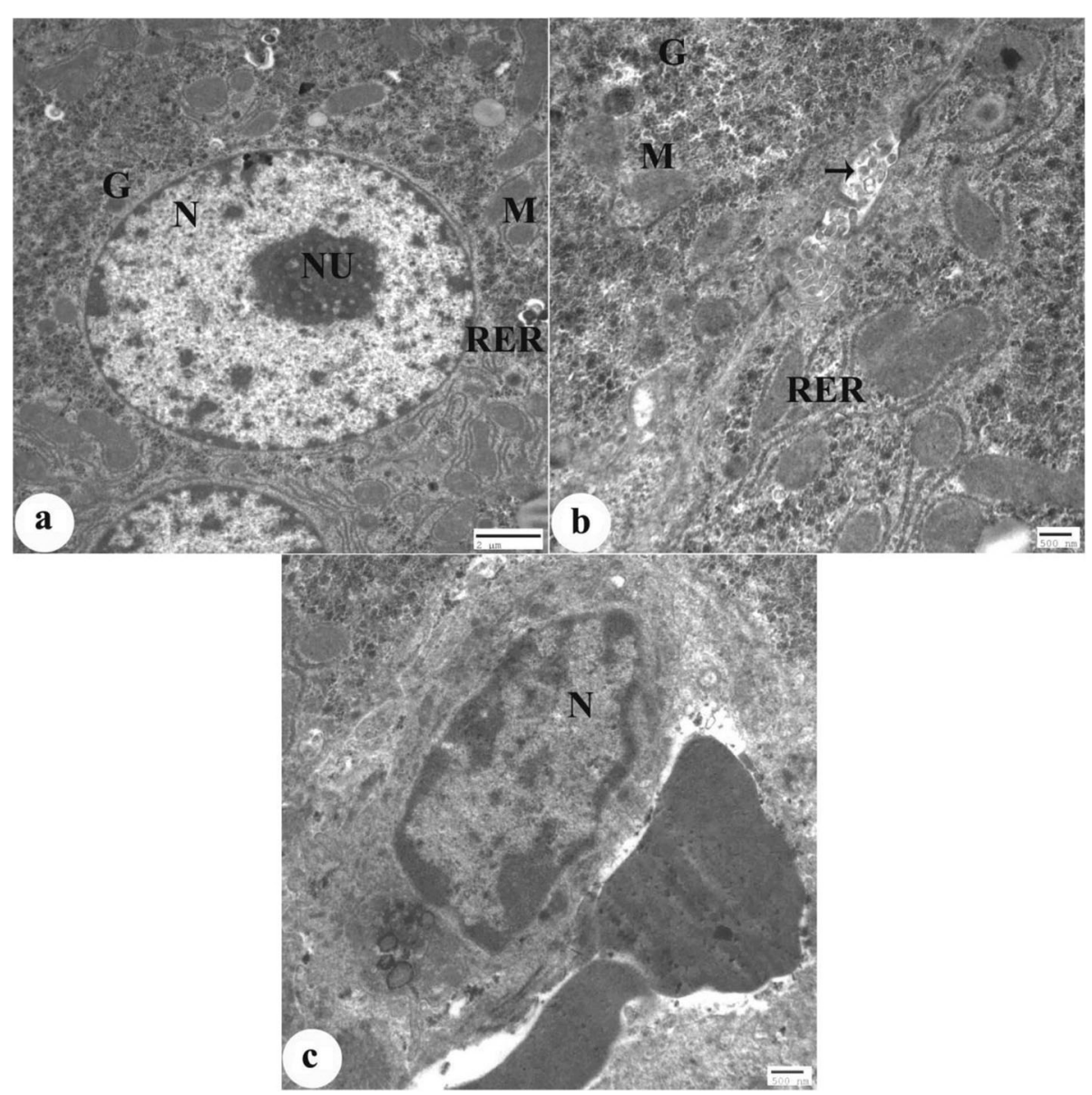

Fig. 8 a-c Electron micrographs of ultrathin sections of liver of control rats showing: normal hepatocyte with normal nucleus (N), nucleolus (NU), rough endoplasmic reticulum (RER), bile duct (arrow) mitochondria (M), glycogen granules (G), and Kupffer cell with nucleus (N). Scale bar = $2 \mu \mathrm{m}, 500 \mathrm{~nm}$, and $500 \mathrm{~nm}$ for $\mathbf{a}, \mathbf{b}$, and $\mathbf{c}$, respectively

in the number of lysosomes in the cytoplasm. These findings were confirmed by Zimnoch et al. [52] and Sulkowska et al. [53] who illustrated that CP treatment leads to a marked polymorphism of the mitochondria and condensation of their matrix, segmentary blurring of the structure of the surrounding membranes, the presence of osmophilic intramitochondrial bodies and paracrystalline structures usually arranged along the organelles. The rough endoplasmic reticulum was focally degranulated, while the smooth endoplasmic reticulum looks as if proliferated and hepatocytes showed regression of changes and gradual normalization.

Alpha-lipoic acid (LA) is a universal antioxidant. Its administration is beneficial in various pathologies in which ROS have been implicated [14, 15]. LA through its powerful antioxidant activity causes a general systemic improvement including liver health [16, 54].

LA scavenges the singlet oxygen, hydrogen peroxide, hydroxyl radicals, and also chelates the ferrous ion involved in the production of hydroxyl radicals [19, 55] and treatment of free radical-related diseases. It is a fact that thiols protect cells against CP-induced LPO [46]. The above reports corroborate well with our findings in experimental hepatotoxicity as treatment with LA showed improvement in levels of LPO and SOD near control groups and elevating level of liver enzymes ALT and AST. From these observations, it is possible to conclude that LA may reduce oxidative stress in CPinduced hepatotoxicity by alleviating lipid peroxidation through scavenging of free radicals or by enhancing the activities of antioxidant enzymes which then detoxify free radicals [19]. So, LA is considered a cytoprotectant in CP-induced hepatic oxidative injury [9].

In our study, rats treated with LA showed an improvement in the histopathology and the ultrastructure of liver sections comparable with CP-treated rats as LA resulted in a marked recovery of the cytoplasm organelles and Kupffer cells restored their normal structure. This protection maybe because of the protective effects of LA against various hepatic injuries [56]. 


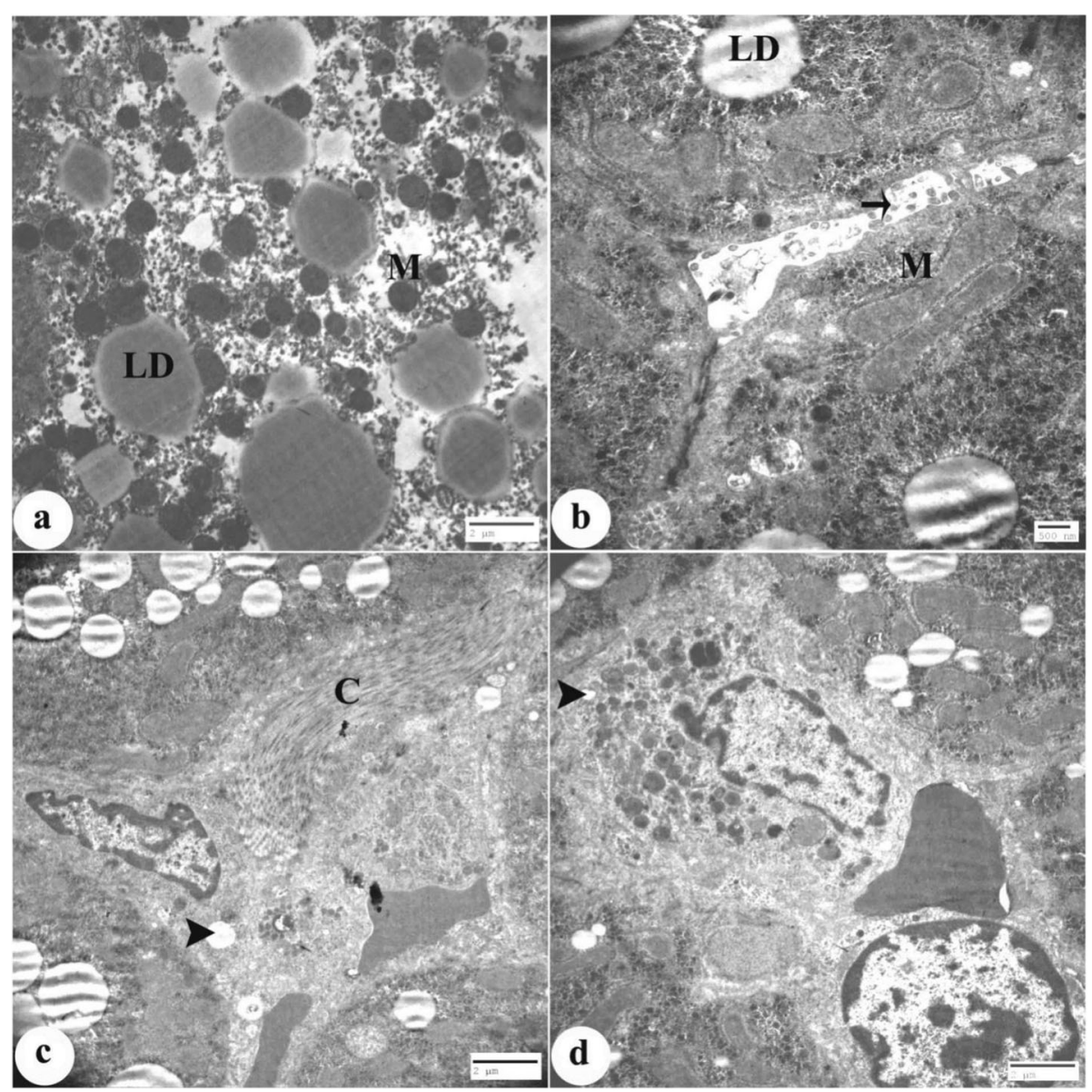

Fig. 9 a-e Electron micrographs of ultrathin section of the liver of CP-treated rats. a Degenerated hepatocytes having multiple small- and medium-sized lipid droplets (LD) and disorganization and decrease in glycogen electron-dense mitochondria (M). $\mathbf{b}$ Dilated damaged bile canaliculus (arrow), some lipid droplets (LD), and swelling and elongated mitochondria with ill-defined cristae (M). c, $\mathbf{d}$ Shrinked nucleus of Kupffer cell, collagen fibers (C), and vacuolation (arrow head) (scale bar $=2 \mu \mathrm{m}, 500 \mathrm{~nm}, 2 \mu \mathrm{m}, 2 \mu \mathrm{m}$, respectively)

Royal jelly (RJ) is a secretion of the hypopharyngeal glands of honeybee workers [57]. It is considered a traditional product commonly used to supplement the medical treatment of various diseases [58]. RJ also has antioxidant [22] and hepatoprotective effects [59].

In the present study, RJ administration, together with $\mathrm{CP}$, leads to elevation of liver enzymes ALT and AST as well as improvement in the level of MDA and SOD in comparison with the $\mathrm{CP}$-treated group. This improvement may be because RJ significantly improved the indices of hepatotoxicity and lipid peroxidation [60] and also because of the hepatoprotective effect of RJ against chemicals known to cause liver damage [61, 62].

$\mathrm{RJ}$ produced a significant protective effect on the liver by decreasing the level of lipid peroxidation (MDA) [63]. In the groups that were administered RJ in association with $\mathrm{CP}$, an improvement was observed in some oxidative stress parameters and certain other biochemical parameters [63].

In our study, liver sections of the RJ-treated group showed an improvement in the hepatic lesions as central vein appeared to have normal structure and both hepatocytes and blood sinusoids nearly appeared similar to control. RJ is a hepatoprotective agent to exhibit a marked protective effect on liver tissue [64]. RJ has been demonstrated to possess numerous pharmacological activities in vitro, in vivo in experimental animals, and through clinical studies, including vasodilative and hypotensive activities, an increase of growth rate, and antitumor, antimicrobial, anti-inflammatory, antihypercholesterolemic activities. Besides, recently, immunomodulatory activities and estrogen-like effects have been published [61].

Treated rats with RJ showed an improvement in the ultrastructure of liver sections comparable with CP- 

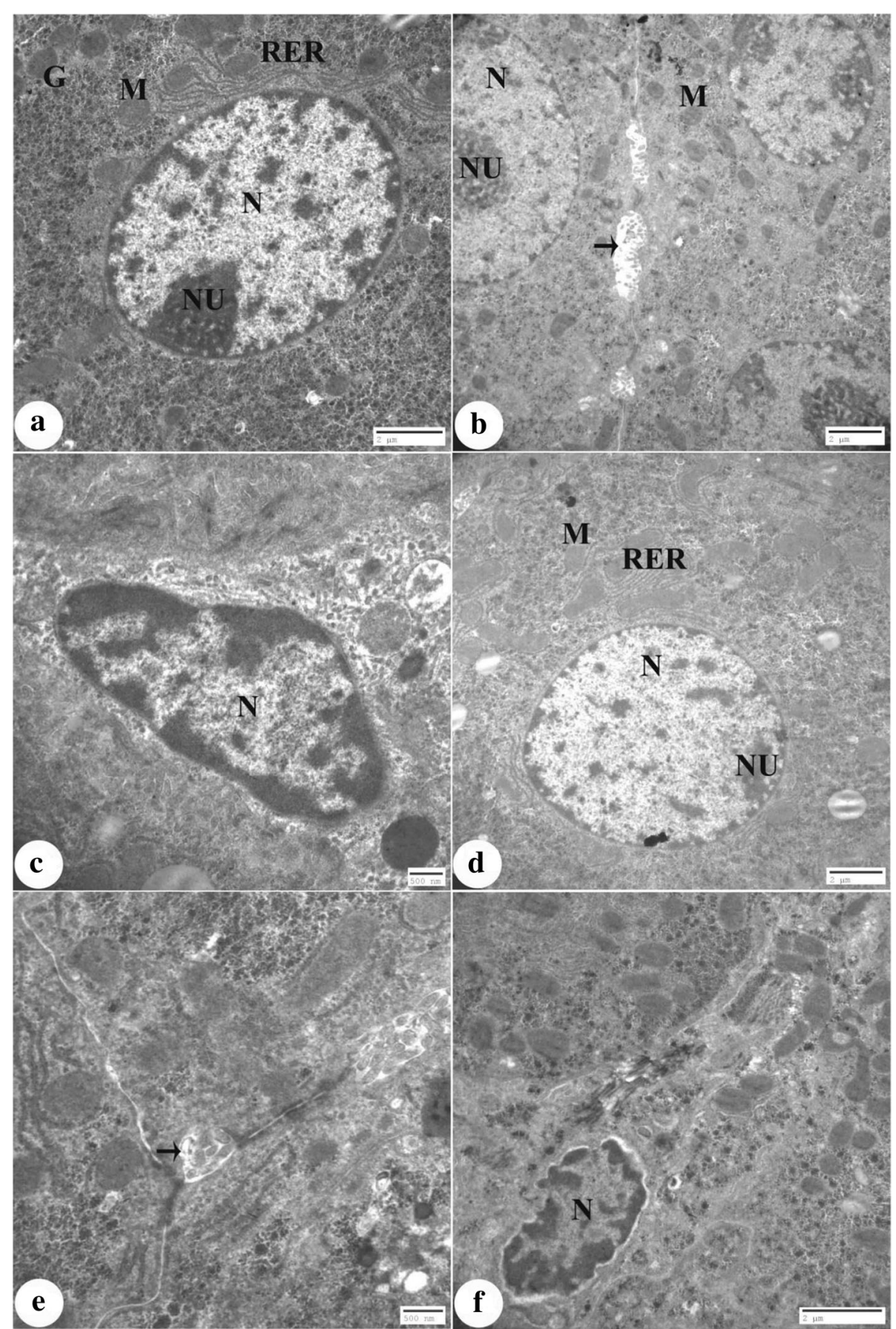

Fig. 10 a-f Electron micrographs of ultrathin section of the liver of CP plus alpha-lipoic acid-(a-c) or royal jelly (d-f)-treated rats showing improvement in liver sections as Kupffer cell restored its normal structure, but Kupffer cell- of royal jelly-treated group showing slightly shrunken nucleus. A marked recovery of the cytoplasm organelles except for a few lipid droplets. Nearly normal appearance of the bile canaliculus

treated rats, whereas there was a noticeable regaining of the cytoplasm organelles except for a few lipid droplets and nearly normal appearance of bile duct, but Kupffer cell showed a shrunken nucleus. This improvement was because RJ contain the $57-\mathrm{kDa}$ glycoprotein which stimulates hepatocyte development and liver regeneration [65] and also was a result of its component vitamins, antioxidant vitamins $\mathrm{A}, \mathrm{E}$, and $\mathrm{C}$; vitamin $\mathrm{D}$; and vitamin B complex [25]. These vitamins themselves had an anticancer effect [66-68]. 


\section{Conclusion}

Little studies founded about the side effects of CP on the ultrastructure of the liver and the protective role of LA and RJ on the ultrastructure of the liver.

Our study recommended that alpha-lipoic acid and royal jelly protect against $\mathrm{CP}$-induced liver damage by their antioxidant effects. Additionally, this study suggested that alpha-lipoic acid and royal jelly may be used parallel with $\mathrm{CP}$ to improve $\mathrm{CP}$-induced injuries in biochemical, histopathology, and ultrastructure of the liver and oxidative stress parameters. Lipoic acid-treated animals showed minimal histologic abnormalities than royal jelly.

\section{Abbreviations \\ CP: Cyclophosphamide; LA: Alpha-lipoic acid; RJ: Royal jelly; MDA: Malonaldehyde; GST: Glutathione transferees; GSH: Glutathione; SOD: Superoxide dismutase; ALP: Alkaline phosphatase; LDH: Lactate dehydrogenase; DMSO: Di methyl sulpho oxide}

\section{Acknowledgements}

Not applicable

\section{Authors' contributions}

All authors have contributed significantly. NM, MA, and KA have contributed in suggesting design of the work, preparation and analysis of the results, and interpretation of data and discussion. In addition, AM has performed the practical part. All authors are in agreement with the contents of the manuscript. All authors read and approved the final manuscript.

\section{Funding}

Not applicable

\section{Availability of data and materials}

All data generated or analyzed during this study are included in this published article.

\section{Ethics approval and consent to participate}

In this study, animal care was carried out following the European Community Directive (86/609/EEC) and national rules; this is in accordance with the NIH guidelines for care and use of laboratory animals, 8th edition. This was administrated by the committee of the Zoology Department, BeniSeuf University, Egypt.

\section{Consent for publication}

Not applicable

\section{Competing interests}

The authors declare that they have no competing interests.

\section{Author details}

${ }^{1}$ Department of Zoology, Faculty of Science, Beni-Suef University, Beni-Suef 62521, Egypt. Pathology Department, Faculty of Veterinary Medicine, Beni-Suef University, Beni-Suef 62521, Egypt.

\section{Received: 5 November 2019 Accepted: 2 March 2020}

Published online: 29 June 2020

\section{References}

1. Cristóvão MB, Torrejais J, Janssens R, Luis P, Van der Bruggen B, Dubey KK et al (2019) Treatment of anticancer drugs in hospital and wastewater effluents using nanofiltration. Sep Purif Technol 224:273-280

2. Araghi A, Golshahi H, Baghban F, AbouhosseiniTabari M (2018) Ameliorative action of farnesol on cyclophosphamide induced toxicity in mice. J Herbmed Pharmacol 7(1)

3. Sharma N, Trikha P, Athar M, Raisuddin S (2000) Inhibitory effect of Emblicaofficinals on the in vivoclastogenicity of benzoalpyrene and acyclophosphamide in mice. Hum Exp Toxicol 19(6):377-384
4. Ayhanci A, Yaman S, Appak S, Gunes S (2009) Hematoprotective effect of seleno-L-methionine on cyclophosphamide toxicity in rats. Drug Chem Toxicol 32(4):424-428

5. Ponticelli C, Locatelli F (2018) Glucocorticoids in the treatment of glomerular diseases: pitfalls and pearls. Clin J Am Soc Nephrol 13(5):815-822

6. Liu X, Chi X, Gong Q, Gao L, Niu Y, Chi X et al (2015) Association of serum level of growth differentiation factor 15 with liver cirrhosis and hepatocellular carcinoma. PLoS One 10(5):e0127518

7. Schwen LO, Schenk A, Kreutz C, Timmer J, Rodriguez MMB, Kuepfer $L$ et al (2015) Representative sinusoids for hepatic four-scale pharmacokinetics simulations. PLoS One 10(7):e0133653

8. Mahmoud MF, Gamal S, El-Fayoumi HM (2014) Limonin attenuates hepatocellular injury following liver ischemia and reperfusion in rats via tolllike receptor dependent pathway. Eur J Pharmacol 740:676-682

9. Selvakumar E, Prahalathan C, Mythili Y, Varalakshmi P (2005) Mitigation of oxidative stress in cyclophosphamide-challenged hepatic tissue by DL-alipoic acid. Mol Cell Biochem 272(1-2):179-185

10. Fahmy MA, Hassan NHA, El-Fiky SA, Elalfy HG (2015) A mixture of honey bee products ameliorates the genotoxic side effects of cyclophosphamide. Asian Pac J Trop Dis 5(8):638-644

11. Pandey AK, Samal MR, Yadav RK, Richichi A, Lata S, Pandey JC, Chen WP (2014) Pre-main-sequence population in NGC 1893 region: X-ray properties. New Astron 29:18-24

12. Anton E (1997) Ultrastructural changes of stromal cells of bone marrow and liver after cyclophosphamide treatment in mice. Tissue Cell 29(1):1-9

13. Ince S, Kucukkurt I, Demirel HH, Acaroz DA, Akbel E, Cigerci IH (2014) Protective effects of boron on cyclophosphamide induced lipid peroxidation and genotoxicity in rats. Chemosphere 108:197-204

14. Midaoui AE, Elimadi A, Wu L, Haddad PS, De Champlain J (2003) Lipoic acid prevents hypertension, hyperglycemia, and the increase in heart mitochondrial superoxide production. Am J Hypertens 16(3):173-179

15. Bjelakovic $\mathrm{G}$ (2007) Mortality in randomized trials of antioxidant supplements for primary and secondary prevention: systematic review and meta-analysis. JAMA 297(8):842-857

16. Pari L, Murugavel P (2004) Protective effect of a-lipoic acid against chloroquine-induced hepatotoxicity in rats. J Applied Toxicol 24(1): 21-26

17. Li Y, Ma QG, Zhao LH, Guo YQ, Duan GX, Zhang JY et al (2014) Protective efficacy of alpha-lipoic acid against aflatoxinB1-induced oxidative damage in the liver. Asian Australas J Anim Sci 27(6):907

18. Feng B, Yan XF, Xue JL, Xu L, Wang H (2013) The protective effects of alpha-lipoic acid on kidneys in type 2 diabetic Goto-Kakisaki rats via reducing oxidative stress. Mol Divers Preserv Int 14:6746-6756

19. Packer L, Witt EH, Tritschler HJ (1995) Alpha-lipoic acid as a biological antioxidant. Free Radic Biol Med 19(2):227-250

20. Khazaei M, Sadeghi MT, Hosseini MS (2018) Stable superhydrophilic coating on superhydrophobic porous media by functionalized nanoparticles. Mater Res Express 5(1):015019

21. Mohamed AA, Azza AAG, Yaser HAE (2015) Comparative protective effects of royal jelly and cod liver oil against neurotoxic impact of tartrazine on male rat pups brain. Acta Histochem 117:649-658

22. El-Nekeety AA, El-Kholy W, Abbas NF, Ebaid A, Amra HA, Abdel-Wahhab MA (2007) Efficacy of royal jelly against the oxidative stress of fumonisin in rats. Toxicon 50(2):256-269

23. Jamnik P, Goranovic D, Raspor P (2007) Antioxidative action of royal jelly in the yeast cell. Exp Gerontol 42:594-600

24. Nakajima Y, Tsuruma K, Shimazawa M, Mishima S, Hara H (2009) Comparison of bee products based on assays of antioxidant capacities. BMC Complement Altern Med 9:4

25. Zimmermann A (2002) Liver regeneration: the emergence of new pathways Med Sci Monit 8:53-63

26. Mythili Y, Sudharsan PT, Sudhahar V, Varalakshmi P (2006) Protective effect of DL-a-lipoic acid on cyclophosphamide induced hyperlipidemic cardiomyopathy. Eur J Pharmacol 543:92-96

27. El-Alfy NZ, Isa M, Mahmoud MF et al (2013) The protective role of the Royal Jelly against histological effects of endoxan drug on the testis of the male albino mice. New York Sci J 6(1):96-101

28. Jalali A, Pipelzadeh MH, Seyedian R, Rahmani AH, Omidian N, Mahdavinia M (2011) In vitro pharmacological study upon the effectiveness of available antivenom against Hemiscorpiuslepturus venom 
29. Rest RF, Cooney MH, Spitznagel JK (1977) Susceptibility of lipopolysaccharide mutants to the bactericidal action of human neutrophil lysosomal fractions. Infect Immun 16(1):145-151

30. Ohkawa H, Ohishi N, Yagi K (1979) Assay for lipid peroxides in animal tissues by thiobarbituric acid reaction. Anal Biochem 95(2):351-358

31. Bancroft JD, Gamble M (2002) Theory and practice of histological techniques. Churchill Livingstone, Edinburgh

32. Glauert AM, Lewis PR (1998) Biological specimen preparation for transmission electron microscopy. Portland press, London

33. Bozzola JJ, Russel LD (1999) Electron microscopy, principles and techniques for biologists. Jones \& Bartlett Learning

34. IBM Corp (2011) IBM SPSS Statistic for windows, Version 20.0. IBMCrop, Armonk

35. Bergmann M, Wendtner CM (2015) Chronic lymphatic leukemia. Dtsch Med Wochenschr 140(7):479-482

36. Dollery C (1999) Cyclophosphamide. In: Dollery C (ed) Therapeutic drugs. Churchill Livingstone, Edinburg, pp 349-353

37. Zhang QH, Wu CF, Duan L, Yang JY (2008) Protective effects of ginsenosideRg 3 against cyclophosphamide-induced DNA damage and cell apoptosis in mice. Arch Toxicol 82(2):117-123

38. Zhang R, Wang L, Yu GR, Zhang X, Yao LB, Yang AG (2009) MicroRNA-122 might be a double-edged sword in hepatocellular carcinoma. Hepatology 50(4):1322-1323

39. Hou WK, Law CC, Yin J, Fu YT (2010) Resource loss, resource gain, and psychological resilience and dysfunction following cancer diagnosis: a growth mixture modeling approach. Health Psychol 29(5):484

40. Drotman R, Lawhan G (1978) Serum enzymes are indications of chemical induced liver damage. Drug Chem Toxicol 1:163-171

41. Tripathi A, Puddick J, Prinsep MR, Lee PPF, Tan LT (2008) Hantupeptin A, a cytotoxic cyclic depsipeptide from a Singapore collection of Lyngbyamajuscula. J Nat Prod 72(1):29-32

42. Vladimir-Knežević S, Blažeković B, Kindl M, Vladić J, Lower-Nedza A, Brantner A (2014) Acetylcholinesterase inhibitory, antioxidant and phytochemical properties of selected medicinal plants of the Lamiaceae family. Molecules 19(1):767-782

43. Bergendi E, Plöchl E, Vlasak I, Rittinger O, Stopar M, Kurnik P, Schiebel K (1999) Clinical, cytogenetic and molecular analysis of three 46, XX males. J Pediatr Endocrinol Metab 12(3):389-396

44. Caglayan C, Temel Y, Kandemir FM, Yildirim S, Kucukler S (2018) Naringin protects against cyclophosphamide-induced hepatotoxicity and nephrotoxicity through modulation of oxidative stress, inflammation, apoptosis, autophagy, and DNA damage. Environ Sci Pollut Res 25(21): 20968-20984

45. Ghosh D, Das UB, Ghosh S, Mallick M, Debnath J (2002) Testicular gametogenic and steroidogenic activities in cyclophosphamide treated rat: a correlative study with testicular oxidative stress. Drug Chem Toxicol 25(3): 281-292

46. Stankiewicz A, Skrzydlewska E, Makiela M (2002) Effects of amifostine on liver oxidative stress caused by cyclophosphamide administration to rats

47. Liu F, Li X, Lin T, He DW, Wei GH, Liu JH et al (2012) The cyclophosphamide metabolite, acrolein, induces cytoskeletal changes and oxidative stress in Sertoli cells. Mol Biol Rep 39(1):493-500

48. Chakraborty P, Sk UH, Murmu N, Das JK, Pal S, Bhattacharya S (2009) Modulation of cyclophosphamide-induced cellular toxicity by diphenylmethylselenocyanate in vivo, an enzymatic study. J Cancer Mol 4(6):183-189

49. Yagmurca M, Bas O, Mollaoglu H, Sahin O, Nacar A, Karaman O, Songur A (2007) Protective effects of erdosteine on doxorubicin-induced hepatotoxicity in rats. Arch Med Res 38(4):380-385

50. Sakr SA, Shalaby SY (2011) Ginger extract protects metalaxyl-induced histomorphological and histochemical alterations in testes of albino mice. J Appl Pharm Sci 1(10):36

51. Cengiz M, Yildiz SC, Demir C, Şahin IK, Teksoy Ö, Ayhanci A (2019) Hepatopreventive and anti-apoptotic role of boric acid against liver injury induced by cyclophosphamide. J Trace Elem Med Biol 53:1-7

52. Zimnoch L, Szynaka B, Rogowski JA, Sulkowski S, Kozielec Z (1997) Ultrastructural studies of the effect of pentoxyfylline on the hepatic cell of the rat with simultaneous administration of cyclophosphamide. Rocz Akad Med Bialymst 42:63-72

53. Sulkowska MARIOLA, Skrzydlewska ELŻBIETA, Sobaniec-Lotowska M Famulski WALDEMAR, Terlikowski SŁAWOMIR, Kanczuga-Koda L,
Daniszewska IRENA (2002) Effect of cyclophosphamide-induced generation reactive oxygen forms on ultrastructure of the liver and lung. Bull Vet Inst Pulawy 46(2):239-246

54. Packer L, Tritschler HJ, Wessel K (1997) Neuroprotection by the metabolic antioxidant alpha-lipoic acid. Free Radic Biol Med 22:359-378

55. Liu G, Liu J, Pian L, Gui S, Lu B (2019) a-lipoic acid protects against carbon tetrachloride-induced liver cirrhosis through the suppression of the TGF- $\beta$ / Smad3 pathway and autophagy. Mol Med Rep 19(2):841-850

56. Hu FL, Bíliková K, Casabianca H, Daniele G, SalmenEspindola F, Feng M et al (2019) Standard methods for Apismellifera royal jelly research. J Apic Res 58(2):1-68

57. Nagai T, Inoue R (2004) Preparation and the functional properties of water extract and alkaline extract of royal jelly. Food Chem 84(2):181-186

58. Uzbekova S, Roy-Sabau M, Dalbiès-Tran R, Perreau C, Papillier P, Mompart F et al (2006) Zygote arrest 1 gene in pig, cattle and human: evidence of different transcript variants in male and female germ cells. Reprod Biol Endocrinol 4(1):12

59. Avus YH, Ching CC (2011) Cyberspace migration: Exploring social network sites switching through human migration theory. J Inf Manag 19(1):105-132

60. Kanbur M, Eraslan G, Beyaz L, Silici S, Liman BC, Altınordulu Ş et al (2009) The effects of royal jelly on liver damage induced by paracetamol in mice. Exp Toxicol Pathol 61(2):123-132

61. Karadeniz A, Simsek N, Karakus E, Yildirim S, Kara A, Can I et al (2011) Royal jelly modulates oxidative stress and apoptosis in liver and kidneys of rats treated with cisplatin. Oxidative Med Cell Longev 2011

62. Silici S, Ekmekcioglu O, Kanbur M, Deniz K (2011) The protective effect of royal jelly against cisplatin-induced renal oxidative stress in rats. World J Urol 29(1):127-132

63. Melliou E, Chinou I (2005) Chemistry and bioactivity of royal jelly from Greece. J Agric Food Chem 53(23):8987-8992

64. Leigh BC (1999) Review of bee products: honey, pollen, propolis and royal jelly. Nutr Sci News 4:366-368

65. Liu B, Jiang JW, Wilson BC, Du L, Yang SN, Wang JY, Hong JS (2000) Systemic infusion of naloxone reduces degeneration of rat Substantianigral dopaminergic neurons induced by intranigral injection of lipopolysaccharide. J Pharmacol Exp Ther 295(1):125-132

66. Klaassen I, Braakhuis BJ (2002) Anticancer activity and mechanism of action of retinoids in oral and pharyngeal cancer. Oral Oncol 38:532-542

67. Giovannucci E, Liu Y, Rimm EB, Hollis BW, Fuchs CS, Stampfer MJ et al (2006) Prospective study of predictors of vitamin D status and cancer incidence and mortality in men. J Natl Canc Inst 98(7):451-459

68. Zou W, Yue P, Lin N, He M, Zhou Z, Lonial S et al (2006) Vitamin C inactivates the proteasome inhibitor PS-341 in human cancer cells. Clin Cancer Res 12(1):273-280

\section{Publisher's Note}

Springer Nature remains neutral with regard to jurisdictional claims in published maps and institutional affiliations.

\section{Submit your manuscript to a SpringerOpen ${ }^{\circ}$ journal and benefit from:}

- Convenient online submission

- Rigorous peer review

- Open access: articles freely available online

- High visibility within the field

- Retaining the copyright to your article

Submit your next manuscript at $>$ springeropen.com 